tion in the social Hymenoptera consists of a co-adaptation of pre-existing sensory mechanisms with patterns of motor activity into systems of communication.

In a paper on the sensitivity limits of photoreceptors, Dr. F. H. C. Marriott (Department of Physiology, Oxford) stressed the necessity of presenting measurements of spectral and absolute threshold sensitivity in such a form that they can be compared throughout the animal kingdom. Such measurements made on five species, namely, man, cat, owl, the amphibian Xenopus, and the flatworm Dendrocoelum, were discussed and compared with special reference to the differences in the visual sensory structures.

Dealing with the problems of the sensory aspects of adaptation in cave animals, Dr. G. Thines (Laboratory of Experimental Psychology, University of Louvain) gave a paper on sensory degeneration and survival in cave fishes. After a critical discussion of the general idea of evolutionary 'progress', Dr. Thines defined regressive changes as a gradual reduction of independence leading to the 'abnormal' character of regressive faunas such as cave fishes. The survival value of regressive changes in photoreceptors in cave fishes was then assessed and this led to the introduction of the hypotheses of 'remanence' and 'vicariance' with regard to the significance of the continuation in eyeless cave fishes of the pre-existing epigean photokinetic functions and of the supplanting of the functionally insufficient eye by the pineal organ. Dr. Thines then showed a short film on the blind fishes of Somaliland.

The design of fish and cephalopod eyes in relation to their environment was discussed by Dr. E. J. Denton (Marine Biological Laboratory, Plymouth). The density, the refractive medium, absorption and scattering of light by the medium all have their effect on the morphology and functional characteristics of the eyes of marine animals. At greater depth and at night the light emitted by luminescent animals may be more important than the light coming from the sky. Light will only be 'useful' for vision if it can be absorbed by photosensitive pigments. Pigments then play an important part in the adaptive specialization of eyes. The elongation of the rods of the deep-sea fish retina, although raising sensitivity, could have an adverse effect on visual acuity were it not for the existence in these elongated rods of marked channelling of light along the rod. Pigment migration between rods also diminishes the blurring effect of lateral spread of light.

The symposium ended with an account by Prof. F. P. Möhres (Department of Comparative Physiology, University of Tübingen) on sonic orientation of bats and other animals. Prof. Möhres recounted how, during the Second World War, Spallanzani's classical observation of orientation of bats in the dark found its explanation in the simultaneous discovery of ultrasonic echo-location in the vespertilionid bats by Griffin, Pierce and Galambos in the United States, by Dijkgraaf in Holland and by himself in Germany, all of them confirming a hypothesis advanced by Hartridge in 1922. In vespertilionid bats short volleys of ultrasonic pulses of a broad and irregular frequency spectrum are utilized in a system of time difference estimation in which the time difference between the emitted signal and its returning echo is a measure of the distance of the reflecting object, and the time difference between the arrival of the echo at the two ears serves as a measure of direction. A completely different sonar mechanism of orientation was, how. ever, discovered by Prof. Möhres to exist in the horse-shoe bats (Rhinolophids). While flying, the horse-shoe bats keep their mouths closed and the horse-shoe points in the direction of flight, or in stationary animals into the direction of 'interest'. Ultrasonic sound, consisting of prolonged cries without frequency or amplitude modulation, is ernitted through the nostrils and cast about in a beam 'focused' by the horse-shoe. In Rhinolophids the essential feature of ultrasonic orientation is thus, according to Prof. Möhres, not a time difference but an intensitydifference estimation. The animals are thus believed to assess the sound intensity of their orientation cries reflected by objects in their environment in turning their ears point to point through the range of space under scrutiny. Rendering the ears immobile abolishes successful orientation. It must be mentioned here, however, that certain aspects of the modus operandi of sonar as summarized by Prof. Möhres are meeting with adverse criticism from a number of quarters.

Finally, Prof. Möhres described how a search for mechanisms intermediate between the vespertilionid and the rhinolophid extremes led to the discovery of intermediate situations in the Hipposideridae and the Megachiroptera (fruit bats). However, no conclusive phylogenetic picture emerged, and the origin and ways of the evolutionary lines remain hidden in the darkness of the past.
O. Lowenstein

\title{
ASPECTS OF OROGENS
}

T WE Geologische Vereinigung held its fiftieth anniversary meeting under the presidency of Prof. G. Fischer in Würzburg during March 12-14. The theme for discussion was the Orogen, the mobile belts or those parts of the Earth's crust in which mountain chains are formed. The process of orogeny can best be considered in respect of time; a time when the materials accumulate and become compacted to form the building materials for the mountains; a time when these rocks are disturbed by forces usually regarded as being produced by shrinking of the Earth's surface; and a time when magmas from deeper horizons within or below the crust break through and pierce the strata whether quiet or crumpled and broken. Part of the magmatic activity consists of the release and movement of reagents which metamorphose the sediments. Then comes a final act in which vertical movements are considerable, helping to account for the present stature of the mountains and their wild or orderly scenery by exposing the various structures to orosion.

There is also a space relationship. The orogens are restricted to comparatively narrow belts in which mountain building takes place. The arrangement of the mountains within these belts is not simple or regular. One reason for this is that earlier chains may have stood along or across the line followed later by younger mountains, and their presence, or that of 
broken fragments of these old ranges, interferes with the growth and orientation of the later ones. The structures themselves may be divided into those formed under comparatively little cover and therefore at low pressure, and others which have formed deep in the crust under high pressure. The former are more often well exposed in present-day mountains, but the latter are seen only where erosion has been unusually deep. The former have often escaped intrusion, but the latter have suffered magmatic injections and are in part complicated by metamorphism.

The forces at work within the orogen also vary. Opinions diverge as to what initiates the commencement of growth, and it is probable that tension played a part. Lateral compression undoubtedly was important during much of its life and resulted in the formation of the folds and associated thrust-faulted structures. At a late stage, however, tension again developed and allowed normal faults to form accom. panied by floods of lava or the great sheets of tuff or voleanic ashes.

Most of the papers delivered during the meeting by some 35 speakers were orthodox enough, but one by Dr. L. Egyed (Budapest) seemed more than a little heretical to some in the audience. He suggested that below the layers of ultrabasic rocks reputed to underlie the sima, there exists less-basic material; magma containing water and other light fugitive constituents which are absent from peridotites. Such ideas appear to be in accord with Dr. Egyed's published views that the Earth is an expanding body, not the contracting one, described, for example, by the late G. M. Lees, which is how many other geologists would have it.

In the opening paper Dr. R. Trumpy (Zurich) remarked that no scheme of mountain building as yet worked out can be applied generally. Each orogen has to be treated as an individual. As well as the disturbing influence exerted by fragments of earlier mountain-chains the type of sediments involved played an important part in determining the shape of the resulting structures. For example, the thick column made up of alternating thin beds of muds and sands, characteristic of eugeosynclines, fold in a totally different style from that found where the strata are mainly thick bodies of limestone and sandstone such as accumulate in miogeosynclines. Examples to illustrate his opinions were chosen from the western Alps which, although well known, are complicated and are by no means typical of structures in some other orogens. Dr. E. K. Walton (Edinburgh) described the eugeosynclinal region of the Scottish Southern Uplands where the Ordovician and Silurian strata are now regarded as being thicker than was previously estimated and as including higher stages in the Silurian than those hitherto recognized there. Broader asymmetrical folds with steep thick flanks and disturbed by large strike faults are commoner structures than the groups of innumerable isoclinal folds depicted in the classical sections by Peach and Horne.

The spilites of the Lahn-Dill region discussed by Dr. H. Hentschel (Wiesbaden) contain albite, chlorite, quartz and calcite instead of the normal minerals of a basaltic suite, plagioclase, pyroxene and olivine. The possibility that sea water entangled among the geosynclinal sediments reacted with basaltic intrusions is considered as probable.

The veteran Dr. P. Eskola (Helsinki) referred to juvenile granites produced by intrusive magmas formed from components from within the Earth which have diffused outwards. These he contrasted with secondary granites derived from re-working of metasomatized sediments or migmatites. These may appear as disharmonic stocks even in epeirogenic regions. The presence of an aureole of contact metamorphism serves to demonstrate cases in which a hotter intrusion pierced a colder environment.

Because the bodies of sial and sima extend laterally as sheets which are nearly horizontal it is easier to imagine the movement of material along rather than across them, but where they are in an unusual rela. tionship, such as occurs near the edge of an orogen where it touches the margin of an ocean basin, transverse movement of magma should be easier. Dr. P. Michot (Liège) directed attention to the importance of such marginal intrusions and suggested that they may originate at depth in the katazone. Now that methods have been devised enabling rapid analyses to be made, Dr. K. R. Mehnert (Berlin) considered that a new and important research tool is available which may be applied to the study of the distribution of alkalis throughout the body of an orogen. Dr. H. Borchert (Clausthal) also spoke of geochemistry, referring to the association of the copper, zinc, lead and barium ores on one hand and chromium, nickel and titanium ores on the other.

The complicated structures of the Central Pyrenees. involving the interpretation of areas with slaty cleavage and of orientation patterns assumed by newly formed metamorphic minerals, were described by Dr. H. J. Zwart (Leyden). Dr. E. Bederke (Göttingen) considered the relationship between stress and regional metamorphic effects. He cited examples from the Sudeten hills and western Alps in which active phases of disturbance were separated by long intervals of quiet. The late history of the orogen was the theme of Dr. A. J. Pannekoek's (Leyden) dis. course. Folding, faulting and differential vertical movements contribute to the present morphology. Theories of mountain building should be capable of explaining the late movements as well as other early ones. The association between late movements and post-orogenic vulcanism suggests the intervention of a magmatic process. The breaking down of a basin like the Mediterranean with excess gravity may be connected with the uplift of neighbouring hills and be independent of the structure of the orogen.

Dr. A. Winkler von Hermaden (Graz) described examples of structures from the western Alps and Croatia, while others chose examples from central Asia, central Africa, the Carpathians, the Balkans, the east Alpine zone and the Ligurian Alps with part of the neighbouring northern Apennines. The object of four other papers was to make use of features seen in Central and South America to show that structures there run nearly parallel to the present coast ; that there has been deposition and folding along an old mass lying to the east; that breaking down accom. panied by intense vulcanism and intrusion has produced a graben-like feature a little inland from the coast; and that large uplifts have taken place rather recently. The frequent earthquakes both out at sea and up to 100 miles inland are taken to indicate that the region is still tectonically active.

During the session the Steinmann Medal was awarded to Prof. H. H. Read. The text of the contributions made by the several speakers is expected to appear in the next volume of the Geologische Rundshau.
J. V. HaRrison 